\title{
The real-word impact of breast and colorectal cancer surgery during the SARS-CoV-2 pandemic
}

\author{
Pasquale Losurdo ${ }^{1,2}$ (D) Natasa Samardzic ${ }^{1} \cdot$ Francesca Di Lenarda $^{1} \cdot$ Nicolò de Manzini $^{1} \cdot$ Fabiola Giudici $^{1}$. \\ Marina Bortul ${ }^{1}$
}

Received: 22 July 2021 / Accepted: 20 November 2021 / Published online: 3 January 2022

(C) Italian Society of Surgery (SIC) 2021

\begin{abstract}
The postponing of screening and the health care system reorganization, due to the Covid-19 pandemic and lockdown, could led to a concerning decline in breast and colorectal cancer diagnoses. This monocentric retrospective analysis has compared the pre-Covid period (March 2019 to March 2020) to the Covid period (April 2020 to April 2021) in terms of screening programs, clinical, surgical and pathological. A total of 799 patients diagnosed with Breast Cancer (BC) and Colorectal Cancer (CRC) underwent surgery during the two periods. In FVG in 2020 a decrease in mammography screening of $17.1 \%$ has been registered compared to 2019; this reduction has been higher for CRC screening, which summed up to $24.5 \%$. As far as BC is concerned, screening-detected tumours rose significantly from 18 to $28 \%$, mastectomies decreased from 40 to $31 \%$ and advanced tumours treated surgically decreased from 12 to $6 \%$. Concerning CRC, a significant increase in admissions through the Emergency Department has been registered in spite of a stable percentage of urgent surgery performed, proving that severely symptomatic patients have been treated adequately. Open surgery has significantly decreased, whereas the tumoral stage and complications have remained constant in the two periods. This study has proved that maintaining standards of care and validated protocols during emergency is the most adequate and winning strategy: impact on BC and $\mathrm{CRC}$ has been less important than expected. These results support the recommendations for immediate and rapid screening program resumption at operating speed, using prioritization strategies to make up for the diagnostic delays.
\end{abstract}

Keywords Breast cancer $\cdot$ Colorectal cancer $\cdot$ SARS-CoV-2 $\cdot$ Breast cancer screening $\cdot$ Colorectal cancer screening

\section{Introduction}

An outbreak of coronavirus disease 2019 (COVID-19), caused by severe acute respiratory syndrome-coronavirus-2 (SARS-CoV-2), has rapidly spread from China to the whole world [1,2]. The World Health Organization declared a public health emergency in late January 2020 and characterized it as a pandemic in March 2020, and the Italian lockdown started on 9th of March.

Pasquale Losurdo and Natasa Samardzic: Equal contribution.

Pasquale Losurdo

palosurdo@gmail.com

1 Surgical Clinic Unit, Department of Medical and Surgical Sciences, Hospital of Cattinara, University of Trieste, Strada di Fiume 447, 34149 Trieste, Italy

2 Department of Surgery, University of Trieste-Ospedale di Cattinara, 34100 Trieste, Italy
Due to lockdown, hospitals were put under emergency state and only oncologic elective surgery and life-saving surgery were performed.

Worldwide, measures to alleviate the burden on healthcare systems, such as the suspension of elective surgeries, were implemented [3]. If possible, elective surgeries were postponed, and the national screening programs for breast and colorectal cancer were temporarily halted starting March $16,2020$.

Screening has been proven to reduce both incidence and mortality of cancer $[4,5]$.

The two major national screening programs, respectively, for colorectal cancer (CRC) and breast cancer (BC), were mostly affected by the reorganization of the Italian health system.

As known, breast and colorectal cancer are two of the most common cancer and the leading cause of cancer death in women and men, respectively, worldwide [6,7]. 
For these reasons, the postponing of screening and the health care system reorganization, could led to a concerning decline in breast and colorectal cancer diagnoses.

This retrospective single-institution study aimed to evaluate the consequences on $\mathrm{CRC}$ and $\mathrm{BC}$ diagnosis and surgery during the pandemic lockdown in a region of Northern Italy highly affected by the severe acute respiratory syndrome-related coronavirus-2 (SARS-CoV-2) virus.

\section{Methods}

\section{Study design}

We consecutively enrolled and retrospectively analyzed a total of 799 patients in our prospective institutional database created with data extracted from "Data-Breast" database of the "Eusoma certified SSD Breast Unit of Trieste and from the Surgical Department of DAI Chirurgia Generale-ASUGI. Of those, 413 underwent surgery from March 2019 to March 2020 and 380 patients underwent surgery from April 2020 till April 2021.

All patients who underwent breast surgery or colorectal surgery from March 2019 to April 2021 were evaluated in our study and investigated separately as the Breast Cancer group (BC group) and the Colorectal Cancer group (CRC group).

Both populations (BC and CRC) were then divided into 2 subgroups: the pre-Covid subgroup (March 2019 and March 2020) and the Covid subgroup (April 2020 and April 2021). March 2020 has been included in the pre-Covid group because patients who underwent surgery during this month had been taken in charge previously and their surgery had already been planned.

\section{Screening program in FVG region}

The current screening program in the Friuli Venezia Giulia region is recommended for all women and men aged 50-69 both for breast $[8,9]$ and colorectal cancer $[10,11]$.

gFOBT is the most basic type of test for CRC screening and became the test of choice in the Friuli Venezia Giulia region after a cost-effectiveness analysis demonstrated its advantages in a mass-screening setting. If positive, gFOBT is followed by a colonoscopy for the final diagnosis [4, 10].

Regarding breast cancer screening, a mammography is the international gold standard. A positive mammography is followed by a second mammography, an ultrasound with fine-needle aspiration cytology (FNAC) or Tru-cut biopsy and a clinical visit $[8,12]$.

\section{Variable and clinical assessment}

For each BC patient, data of diagnosis (mammography, ultrasound, cytological examination and magnetic resonance), admission and surgery were collected. Surgical procedures were distinguished between breast conservative surgery and breast invasive surgery.

Patients without clinical or radiological evidence of lymph nodes involvement underwent sentinel lymph node biopsy (SLNB). Otherwise, patients with axillary involvement or SLNB positivity underwent axillary lymph node dissection (ALND) [13].

Data from surgical specimens were included in the study according to Pathological staging based on recommendations from AJCC 2018 (edition VIII) for TNM classification [14] and according to the Nottingham Histologic Score system [15].

For each CRC patient, the date of surgery and discharge were collected. Data regarding diagnostic procedures were included: screening program, out of screening FOBT, colonoscopy, Emergency Department admission were the possible alternatives as first diagnostic procedures that were carried out. Strictly connected to this was the evaluation of the surgical regimen: either elective or urgent.

Data from surgical specimens were included in the study. Pathological staging was based on recommendations from AJCC 2018 (edition VIII) for TNM classification [16].

Finally, patients whose diagnosis was changed to nontumoral after histological analysis were ruled out, for a total of 13 out of 263 .

\section{Statistical analysis}

Descriptive statistics were used to describe the patient and treatment characteristics. Continuous variables distribution was checked for normality with the Shapiro-Wilk test, then data were presented as mean and standard deviations (SD) if normally distributed, or median and range (minimum-maximum) if not. Categorical variables were summarized with absolute frequencies and percentages. Clinical and pathological characteristics were compared between two times periods (March 2020 to March 2021 vs April 2020 to April 2021): continuous variables were analyzed thorough Mann-Whitney nonparametric test, while qualitative variables by means of Chi-squared test or Fischer-exact test when appropriate. Percentage variation between months was investigated with the proportion test. Two-sided $p$ values $<0.05$ were considered statistically 
significant and all calculations were performed using $\mathrm{R}$ software version 4.0.3 (2020).

\section{Results}

\section{Characterization of patients enrolled on cancer screening and surgical activity}

Globally, in Table 1 (column A) we report a reduction of $17.1 \%$ of breast cancer screening in the FVG region with 57 missed diagnosis of breast cancer.

Regarding colorectal cancer, we report a reduction of $24.5 \%$ of CRC screening in our region, 24 missed diagnoses of cancer and 100 missed diagnoses of advanced adenomas (Table 1 column B).

Starting from March 2020, the next five months had a reduction in activity as far as General Surgery is concerned which saw less than 115 patients undergoing surgery and other 5 months saw an even more drastic reduction, as less than 100 procedures were performed (Table 2).

Overall, 1723 surgical procedures were performed from March 2019 to March 2020 and 1420 were performed from April 2020 to April 2021, with a total reduction of $17.6 \%$, not considering day surgery (Table 2 ).

\section{Breast cancer}

\section{Screening activity}

Mammography tests saw a reduction of $17.1 \%$ in 2020 as far as FVG's Regional organised screening is concerned. This brings to an estimated reduction in the diagnosis of 57 breast cancers, which is far better than overall Italian regions' median data (Table 1 column A).

51 individuals out of 281 (18.2\%) in the pre-Covid period and 76 out of 264 (28.4\%) in the Covid period took the screening test out of patients operated for breast cancer $(p$ value 0.005$)$.

\section{Impact of Covid era in the breast cancer surgery}

As disclosed in Table 3, we reported a reduction of $4.6 \%$ in terms of BC surgery. 281 patients underwent surgery from March 2019 to March 2020, as opposed to 268 from April 2020 to April 2021.

Comparing stage's distribution between pre- and Covid periods, less stage III and IV (advanced stage) breast cancers were diagnosed in the COVID period (6.3 vs $12.4 \%$, $p=0.02$ ).

There are significant data regarding changes in type of surgery during the Covid period as opposed to the pre-Covid period (Table 3). During the pre-Covid period conservative

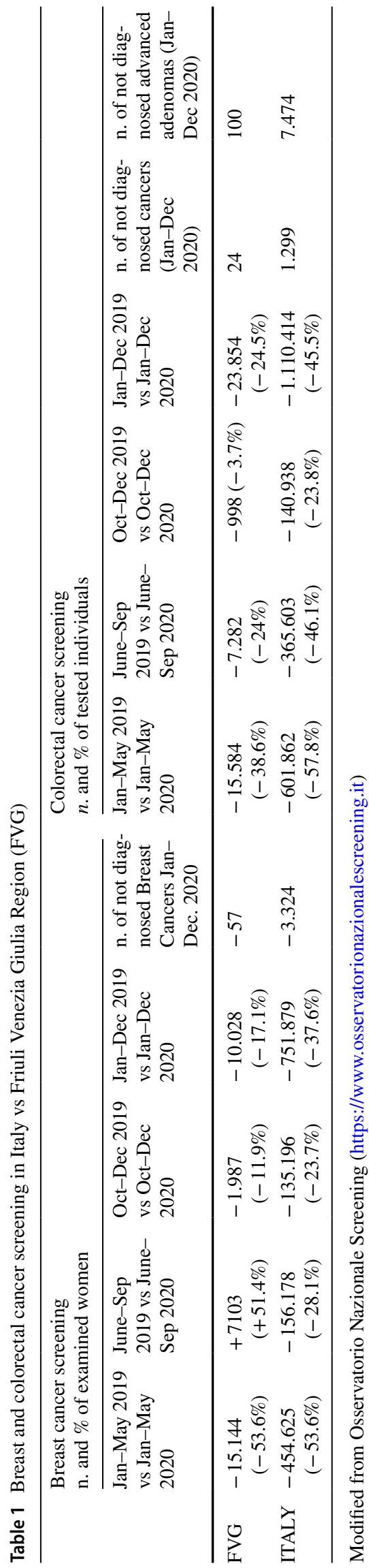


Table 2 General surgical activity

\begin{tabular}{llllll}
\hline Month & $\begin{array}{l}\text { n. of surgical } \\
\text { procedures }\end{array}$ & Month & n. of surgical procedures & Variation in \% & $\begin{array}{c}\text { Month } \\
\text { n. of surgical } \\
\text { procedures }\end{array}$ \\
\hline March 2019 & 127 & March 2020 & 113 & $-11.0 \%$ & March 2021 \\
April 2019 & 129 & April 2020 & 95 & $-26.4 \%$ & April 2021 \\
May 2019 & 140 & May 2020 & 111 & $-20.7 \%$ & $-21.7 \%$ \\
June 2019 & 138 & June 2020 & 108 & $-4.8 \%$ \\
July 2019 & 146 & July 2020 & 139 & $-33.1 \%$ \\
August 2019 & 124 & August 2020 & 83 & $0.7 \%$ \\
September 2019 & 136 & September 2020 & 137 & $2.4 \%$ \\
October 2019 & 127 & October 2020 & 130 & $-21.4 \%$ \\
November 2019 & 126 & November 2019 & 99 & $-19.3 \%$ \\
December 2019 & 140 & December 2020 & 113 & $-20.3 \%$ \\
January 2020 & 133 & January 2021 & 106 & $-36.1 \%$ \\
February 2020 & 144 & February 2021 & 92 & \\
\hline
\end{tabular}

Values are \% monthly variation in surgical activity

surgery made up $60.5 \%$ of all the surgical operations, with $39.5 \%$ of mastectomies ( $p$ value 0.03 ).

In the Covid period instead, conservative surgery arouses to $69.0 \%$ and mastectomies decreased to $31.0 \%$ ( $p$ value $0.03)$.

No statistically significant changes were observed in terms of reconstruction and axillary dissection.

\section{Colorectal cancer}

\section{Screening activity}

gFOBT and subsequent colonoscopies saw a reduction of $24.5 \%$ in 2020 as far as FVG's Regional organised screening is concerned. This brings to an estimated reduction in the diagnosis of 24 colorectal cancers and 100 advanced adenomas, which is still much better than the overall Italian region's median data (Table 1 column $\mathrm{B}$ ).

As reported in Table 4, FOBT and colonoscopies performed out of the screening regimen were much higher in number in both the first and second period of interest.

Respectively, 42/132 FOBT tests (33.1\%) and 37/118 $(31.9 \%)$ were performed during the first and second period, with a slight and not significant decrease.

Colonoscopies were performed in even more cases, as expected: respectively $112 / 132(86.2 \%)$ and $100 / 118$ $(84.5 \%)$ were performed, respectively, during the first and second period, with a slight decrease.

\section{Patients' characteristics}

Our data (Table 4) show that out of all the patients operated for colorectal cancer, 22 individuals out of 132 (17.5\%) in the pre-Covid period and 18 out of $118(15.8 \%)$ in the Covid period took the screening test.

132 cases underwent surgery from March 2019 to March 2020, as opposed to 118 from April 2020 to April 2021. This sums up to a total reduction of $10.6 \%$ of CRC surgery comparing pre-Covid and Covid period.

During the Covid period, more than $20 \%$ of patients with colorectal cancer as opposed to the pre-Covid period were admitted in an emergency through the Emergency Department $(33.3$ vs $53.4 \% ; p$ value $=0.001)$.

A borderline significant increase from 6.8 to $10.2 \%$ of left hemicolectomy surgery has been observed, compared to a decrease from 56.1 to $50.0 \%$ of right hemicolectomy surgery.

Regarding surgical treatment, in the Covid period a not significantly changes in the surgical approach was reported.

We noticed a $7 \%$ decrease of reinterventions (from $12.9 \%$ in the pre-Covid period to $5.9 \%$ in the Covid period, $p$ value $=0.06$ ) and non-significant data concerns terminal ostomies and Dindo-Clavien classification.

\section{Tumour characteristics}

There is a trend towards greater lymph node involvement in the Covid period $(p=0.096)$. This is also confirmed by observing the stages: II, III, IV stages (which are N+) have seen an increase in a number of cases in the Covid period as opposed to the previous one.

The comparison between early stages $(0-\mathrm{I}-\mathrm{II})$ and advanced stages (III-IV) resulted in a decrease in early stages (59.1-49.1\%) and an increase in advanced stages (40.9-50.9\%).

Lastly, T0, T1 and T2 have decreased in number as opposed to T3 and T4. The greatest change is to be seen 
Table 3 Characterization of patients with breast cancer

\begin{tabular}{|c|c|c|c|}
\hline Variables & $\begin{array}{l}\text { Pre Covid: } \\
\text { Mar 2019-Mar } 2020 \\
(n=281)\end{array}$ & $\begin{array}{l}\text { Covid period: } \\
\text { Apr 2020-Apr } 2021 \\
(n=268)\end{array}$ & $p$ value \\
\hline \multicolumn{4}{|l|}{ General characteristics } \\
\hline $\begin{array}{l}\text { Age } \\
\text { Median (min-max) }\end{array}$ & $65(35-90)$ & $63(30-97)$ & 0.25 \\
\hline $\begin{array}{l}\text { Symptomatic }(N, \%) \\
\text { Yes }\end{array}$ & $164(58.4 \%)$ & $141(52.6 \%)$ & 0.17 \\
\hline $\begin{array}{l}\text { Screening }(N, \%) \\
\quad \text { Yes }\end{array}$ & $51(18.2 \%)$ & $76(28.4 \%)$ & $0.005^{*}$ \\
\hline \multicolumn{4}{|l|}{ Pre-surgery } \\
\hline $\begin{array}{l}\text { Diagnostic exam }(N, \%) \\
\text { Only FNAC } \\
\text { Only core biopsy } \\
\text { FNAC + core biopsy }\end{array}$ & $\begin{array}{l}67(23.8 \%) \\
91(32.4 \%) \\
123(43.8 \%)\end{array}$ & $\begin{array}{l}59(22.0 \%) \\
71(26.5 \%) \\
138(51.5 \%)\end{array}$ & 0.17 \\
\hline $\begin{array}{l}\text { Neoadjuvant CT }(N, \%) \\
\quad \text { Yes }\end{array}$ & $12(4.3 \%)$ & $20(7.5 \%)$ & 0.11 \\
\hline \multicolumn{4}{|l|}{ Surgery outcomes } \\
\hline $\begin{array}{l}\text { Type of surgery }(N, \%) \\
\text { Conservative } \\
\text { Mastectomy }\end{array}$ & $\begin{array}{l}170(60.5 \%) \\
111(39.5 \%)\end{array}$ & $\begin{array}{l}185(69.0 \%) \\
83(31.0 \%)\end{array}$ & $0.03^{*}$ \\
\hline Immediate reconstruction after MT & $60(54.1 \%)$ & $48(57.8 \%)$ & \\
\hline $\begin{array}{l}\text { Sentinel lymph node biopsy } \\
\text { Axillary dissection }\end{array}$ & $\begin{array}{l}230(81.9 \%) \\
47(16.7 \%)\end{array}$ & $\begin{array}{l}235(87.7 \%) \\
39(14.6 \%)\end{array}$ & 0.05 \\
\hline & & & 0.48 \\
\hline \multicolumn{4}{|l|}{ Tumor characteristics } \\
\hline $\begin{array}{l}\text { Type of tumor: } \\
\text { Invasive } \\
\text { In situ }\end{array}$ & $\begin{array}{l}242(87.2 \%) \\
36(12.8 \%)\end{array}$ & $\begin{array}{l}243(90.7 \%) \\
25(9.3 \%)\end{array}$ & 0.19 \\
\hline $\begin{array}{l}\text { Histology } \\
\text { Ductal }\end{array}$ & $\begin{array}{l}175(71.4 \%) \\
40(16.3 \%)\end{array}$ & $\begin{array}{l}174(71.9 \%) \\
41(16.9 \%)\end{array}$ & 0.9 \\
\hline Lobular & $9(3.7 \%)$ & $6(2.5 \%)$ & \\
\hline Ductal-Lobular & $21(8.6 \%)$ & $21(8.7 \%)$ & \\
\hline \multicolumn{4}{|l|}{$\mathrm{pT}(N, \%)$} \\
\hline pTis & $36(12.8 \%)$ & $25(9.3 \%)$ & 0.32 \\
\hline 1 & $165(58.7 \%)$ & $164(612 \%)$ & \\
\hline 2 & $59(21.0 \%)$ & $49(18.3 \%)$ & \\
\hline $03-\mathrm{Apr}$ & $9(3.2 \%)$ & $10(3.7 \%)$ & \\
\hline урТ & $12(4.3 \%)$ & $20(7.5 \%)$ & \\
\hline $\mathrm{pN}(N, \%)$ & & & 0.05 \\
\hline N0-N1mi & $213(78.9 \%)$ & $222(84.7 \%)$ & \\
\hline N1 & $34(12.6 \%)$ & $30(11.5 \%)$ & \\
\hline $\mathrm{N} 2-\mathrm{N} 3$ & $23(8.5 \%)$ & $10(3.8 \%)$ & \\
\hline Stage $(N, \%)$ & & & 0.02 \\
\hline Early (0-I-II) & $205(87.6 \%)$ & $222(93.8 \%)$ & \\
\hline Advanced (III-IV) & $29(12.4 \%)$ & $15(6.3 \%)$ & \\
\hline Molecular subtype & & & 0.5 \\
\hline Luminal A & $100(41.0 \%)$ & $112(46.7 \%)$ & \\
\hline Luminal B Her2- & $88(36.1 \%)$ & $77(32.1 \%)$ & \\
\hline Her $2+$ & $31(12.7 \%)$ & $24(10.0 \%)$ & \\
\hline Triple negative & $25(10.3 \%)$ & $27(11.3 \%)$ & \\
\hline
\end{tabular}

Values are mean $\mathrm{SD}, \%$, or median [interquartile range]

*Statistically significant difference between pre-covid and covid period for BC 
Table 4 Characterization of patients with colorectal cancer

\begin{tabular}{|c|c|c|c|}
\hline Variables & $\begin{array}{l}\text { Pre Covid: } \\
\text { Mar 2019-Mar } 2020 \\
(n=132)\end{array}$ & $\begin{array}{l}\text { Covid period: } \\
\text { Apr 2020-Apr } 2021 \\
(n=118)\end{array}$ & $p$ value \\
\hline \multicolumn{4}{|l|}{ General characteristics } \\
\hline Age & & & 0.71 \\
\hline Median (min-max) & $77.0(47-94)$ & $77.5(32-93)$ & \\
\hline $\operatorname{Sex}(N, \%)$ & & & 0.58 \\
\hline M & $68(51.5 \%)$ & $57(48.3 \%)$ & \\
\hline Screening $(N, \%)$ & & & 0.73 \\
\hline Yes & $22(17.5 \%)$ & $18(15.8 \%)$ & \\
\hline $\operatorname{SOF}(N, \%)$ & & & 0.85 \\
\hline Yes & $42(33.1 \%)$ & $37(31.9 \%)$ & \\
\hline Colonscopy $(N, \%)$ & & & 0.75 \\
\hline Yes & $112(86.2 \%)$ & $100(84.5 \%)$ & \\
\hline ER admission $(N, \%)$ & $44(33.3 \%)$ & $63(53.4 \%)$ & $0.001 *$ \\
\hline \multicolumn{4}{|l|}{ Pre-surgery } \\
\hline CA.19.9.preop & & & 0.58 \\
\hline Median (min-max) & $11.8(0.8-1902.0)$ & $10.6(0.8-1310.1)$ & \\
\hline CEA preop & & & 0.75 \\
\hline Median (min-max) & $2.5(0.4-634.0)$ & $2.5(0.6-913.9)$ & \\
\hline Charlson score $(N, \%)$ & & & 0.43 \\
\hline Median (min-max) & $6(2-16)$ & $6(2-11)$ & \\
\hline ASA score $(N, \%)$ & & & 0.99 \\
\hline 01-Feb & $91(68.9 \%)$ & $81(68.6 \%)$ & \\
\hline 03-Apr & $41(31.1 \%)$ & $37(31.4 \%)$ & \\
\hline Neoadjuvant CT $(N, \%)$ & & & $0.05^{*}$ \\
\hline Yes & $2(1.5 \%)$ & $8(6.8 \%)$ & \\
\hline Neodjuvant RT $(N, \%)$ & & & 0.56 \\
\hline Yes & $5(3.8 \%)$ & $7(5.9 \%)$ & \\
\hline \multicolumn{4}{|l|}{ Surgery outcomes } \\
\hline Emergency/urgency setting $(N, \%)$ & $24(18.1 \%)$ & $25(21.2 \%)$ & 0.55 \\
\hline Site of surgery $(N, \%)$ & & & 0.05 \\
\hline Right hemicolectomy & $74(56.1 \%)$ & $59(50.0 \%)$ & \\
\hline Left hemicolectomy & $9(6.8 \%)$ & $12(10.2 \%)$ & \\
\hline Rectal resection & $27(20.5 \%)$ & $30(25.4 \%)$ & \\
\hline Segmentary resection & $12(9.1 \%)$ & $4(3.4 \%)$ & \\
\hline Transverse resection & $4(3.3 \%)$ & $9(7.6 \%)$ & \\
\hline Hartmann & $6(4.6 \%)$ & $1(0.9 \%)$ & \\
\hline Transverse ostomy & $0(0.0 \%)$ & $2(1.7 \%)$ & \\
\hline Colostomy & $0(0.0 \%)$ & $1(0.9 \%)$ & \\
\hline Access $(N, \%)$ & & & $0.003 *$ \\
\hline Open & $52(39.4 \%)$ & $42(35.6 \%)$ & \\
\hline Laparoscopic & $80(60.6 \%)$ & $66(55.9 \%)$ & \\
\hline Robotic & $0(0.0 \%)$ & $10(8.5 \%)$ & \\
\hline Anastomosis $(N, \%)$ & & & 0.42 \\
\hline Yes & $122(92.4 \%)$ & $112(94.9 \%)$ & \\
\hline Type of anastomosis $(N, \%)$ & & & 0.08 \\
\hline Manual & $49(40.2 \%)$ & $32(28.6 \%)$ & \\
\hline Mechanic/semi-mechanic & $73(59.8 \%)$ & $80(71.4 \%)$ & \\
\hline
\end{tabular}


Table 4 (continued)

\begin{tabular}{|c|c|c|c|}
\hline Variables & $\begin{array}{l}\text { Pre Covid: } \\
\text { Mar 2019-Mar } 2020 \\
(n=132)\end{array}$ & $\begin{array}{l}\text { Covid period: } \\
\text { Apr 2020-Apr } 2021 \\
(n=118)\end{array}$ & $p$ value \\
\hline Intra-extra corporea $(N, \%)$ & & & 0.65 \\
\hline Extra & $70(57.4 \%)$ & $61(54.5 \%)$ & \\
\hline Intra & $52(42.6 \%)$ & $51(45.5 \%)$ & \\
\hline $\operatorname{ICG}(N, \%)$ & & & 0.13 \\
\hline Yes & $72(54.6 \%)$ & $75(64.1 \%)$ & \\
\hline Reintervention $(N, \%)$ & & & 0.06 \\
\hline Yes & $17(12.9 \%)$ & $7(5.9 \%)$ & \\
\hline Stomia di Protezione $(N, \%)$ & & & 0.76 \\
\hline Yes & $15(11.4 \%)$ & $12(10.2 \%)$ & \\
\hline Stomia Terminale $(N, \%)$ & & & 0.98 \\
\hline Yes & $9(6.9 \%)$ & $8(6.8 \%)$ & \\
\hline Wound classification $(N, \%)$ & $86(65.2 \%)$ & $68(57.6 \%)$ & \\
\hline Clean/contaminated & $30(22.7 \%)$ & $23(19.5 \%)$ & \\
\hline Contaminated & $13(9.9 \%)$ & $20(17.0 \%)$ & \\
\hline Dirty/infected & $3(2.3 \%)$ & $7(5.9 \%)$ & \\
\hline Drenaggio $(N, \%)$ & $67(51.2 \%)$ & $62(53.0 \%)$ & 0.77 \\
\hline Yes & & & \\
\hline Duration of surgery (min) & & & 0.22 \\
\hline Median (min-max) & $180(70-480)$ & $205(50-430)$ & \\
\hline Dindo-CLavien $(N, \%)$ & & & 0.23 \\
\hline I & $82(62.1 \%)$ & $83(70.3 \%)$ & \\
\hline II & $28(21.2 \%)$ & $23(19.5 \%)$ & \\
\hline III & $16(12.1 \%)$ & $6(5.1 \%)$ & \\
\hline IV-V & $6(4.6 \%)$ & $6(5.1 \%)$ & \\
\hline Number of positive nodes & & & 0.29 \\
\hline Median (min-max) & $4(1-51)$ & $2(1-18)$ & \\
\hline \multicolumn{4}{|l|}{ Stage } \\
\hline \multicolumn{4}{|l|}{$\mathrm{pT}(N, \%)$} \\
\hline $0-1$ & $18(13.6 \%)$ & $13(11.0 \%)$ & 0.28 \\
\hline 2 & $28(21.2 \%)$ & $16(13.6 \%)$ & \\
\hline 3 & $61(46.2 \%)$ & $59(50.0 \%)$ & \\
\hline 4 & $25(18.9 \%)$ & $30(25.4 \%)$ & \\
\hline $\mathrm{pN}(N, \%)$ & & & $0.23^{*}$ \\
\hline NO & $82(62.1 \%)$ & $61(51.7 \%)$ & \\
\hline N1 & $28(21.2 \%)$ & $34(28.8 \%)$ & \\
\hline N2 & $22(16.7 \%)$ & $23(19.5 \%)$ & \\
\hline $\mathrm{pM}(N, \%)$ & & & 0.7 \\
\hline 1 & $20(15.2 \%)$ & $20(17.0 \%)$ & \\
\hline Stage $(N, \%)$ & & & 0.35 \\
\hline $0-\mathrm{I}$ & $39(29.6 \%)$ & $25(21.2 \%)$ & \\
\hline II & $39(29.6 \%)$ & $33(27.0 \%)$ & \\
\hline III & $34(25.8 \%)$ & $40(33.9 \%)$ & \\
\hline IV & $20(15.2 \%)$ & $20(17.0 \%)$ & \\
\hline Stage $(N, \%)$ & & & 0.09 \\
\hline Early (0-I-II) & $78(59.1 \%)$ & $58(49.1 \%)$ & \\
\hline Advanced (III-IV) & $54(40.9 \%)$ & $60(50.9 \%)$ & \\
\hline
\end{tabular}

Values are mean SD, \%, or median [interquartile range]

*Statistically significant difference between pre-covid and covid period for CRC 
in the $\mathrm{T} 2 \mathrm{~s}(-6.6 \%)$ and in the $\mathrm{T} 4 \mathrm{~s}(+6.5 \%)$ : in the Covid period an increase of $10.2 \%$ was registered in $\mathrm{T} 3$ and $\mathrm{T} 4$ tumours, respectively, to the pre Covid period (75.4 vs $65.2 \%, p=0.079)$.

\section{Discussion}

COVID-19 has dramatically impacted medicine and surgery, including surgical oncology. A cross-sectional study included patients across the United States demonstrated a $46 \%$ decrease in new cancer diagnoses during March and April 2020 among 6 common malignancies, including breast and colorectal cancer [17].

It has been observed internationally that COVID-19 had a great impact on cancer screening rates, reduced health service use and a consequent delay in diagnoses.

Several published papers, report a decrease in total and new cancer patient, due to the screening, during the COVID19 period. In particular, decreases in cancer screening have been reported for lung [18], breast [19] and colon cancer $[20,21]$.

The Netherlands Cancer Registry noted an almost 30\% decrease in new cancer diagnoses in all primary cancer sites [22]. New cancer diagnoses remained low, despite a national public awareness campaign to increase cancer diagnoses by encouraging patients to discuss new symptoms with their primary care provider, encouraging primary care providers to refer patients to oncology specialist, and resuming cancer screening operations [22].

The aim of this study was to evaluate the overall impact of the COVID-19 pandemic lockdown on the diagnosis and surgery of BC and CRC after the disruption of the screening programs and health care system reorganization in our region.

Day surgery activity for benign pathologies was stopped, completely, with a reduction of 100\% since March 2019.

Overall, a reduction of $17.6 \%$ was noticed, but even if less cancer patients underwent surgery, relatively speaking, the percentage, as opposed to the year before, was higher, both for BC and CRC.

Scuola Superiore Sant'Anna and AGENAS published a study [17] on the 29th of May regarding regional Resilience towards COVID-19 pandemic concerning the oncological (screening and surgery) and cardiological pathologies. As far as programmed surgical volumes are concerned comparing the periods March 2019 to June 2019 and March 2020 to June 2020, this study observed a decrease of $50 \%$ in FVG, which, compared to other Italian regions, is lower than the average.

As far as the breast cancer regional screening program is concerned, a reduction of only $17.1 \%$ was registered in 2020 as opposed to 2019. Between June and September, a great number of mammography tests was performed due to the change in recruitment: 76 phone calls a day were made to arrange mammography and for each patient three phone calls are provided: if they do not answer the first and second call, a third one is done to make sure recruitment is done efficiently.

In the same study [17] mentioned above, FVG was reported to be the best Italian region in terms of making up for the delay. This analysis has been done comparing January 2019 to September 2019 to January 2020 to September 2021, which is not scientifically correct, considering COVID-19 aroused in our State in March 2020.

The median percentage of adhesion to the colorectal screening program in $\mathrm{FVG}$ is $65 \%$, to which we have to add a $5 \%$ of privately performed colorectal tests. Colorectal regional screening has always been less considered from the general population, even if FVG has one of the highest rates of participation as far as Italian regions are concerned. The annual difference between 2019 and 2020 saw a reduction of $24.5 \%$. Starting from a lower percentage of adhesion (partially due to a less active campaign to raise awareness and to do the more invasive tests), a greater reduction as opposed to mammography tests was noticed and this is due to various factors:

1. Suspension of the regional screening program (first level test-gFOBT) for a longer period;

2. Longer suspension of second-level test because of fear of infection due to the invasive procedures

3. Greater fear of more invasive second-level tests that require a longer stay in the hospital (which means a longer possible exposure to the Covid-19 virus);

4. Worse organisation in the regional screening service: not all who didn't receive the invitation to perform the test have been called back.

Regarding BC surgery in the COVID-19 period we saw an increase in conservative surgery and decrease in mastectomies; a higher percentage of screening-detected BC is compliant with less invasive surgery and reflects the effectiveness of the screening program.

Lastly, being a Eusoma (European Society of Breast Cancer Specialists) certified center [23, 24], it is interesting to observe how quality indicators (data not showed) have not changed from 2019 to 2020, confirming the quality of Trieste's Breast Unit and its resilience to the COVID-19 pandemic [25].

In relation to the CRC surgery, there was a total reduction of $10.6 \%$ of activity if compared to the pre-Covid period. A significantly greater number of patients with CRC underwent urgent surgery in the COVID-19 period compared to the pre-COVID era ( $p$ value $=0.001)$. 
As far as the second point is concerned, the second possibility to come to an early CRC diagnosis after screening tests is to give value, recognize and refer to mild symptoms such as constipation and asthenia. In a pandemic reality, General practitioners could not receive patients in a visit as frequently and securely as before and patients themselves preferred not to go to the hospital, being afraid of being infected. This led to an increase of more severely symptomatic patients, which also borderline statistically correlates to a higher volume of cancer mass and infiltration.

Even though only borderline significant, advanced stages grew from 40.9 to $50.9 \%$, with a symmetrical decrease in early stages, from 59.1 to $49.1 \%$.

Finally, in the Scuola Superiore Sant'Anna and AGENAS' study [17], a comparison between March 2019-June 2019 and March 2020-June 2020 as far as Colon cancer and Rectal cancer has been made and, in both cases, surgical volume was higher than the Italian average.

More severe presentations, more advanced CRCs, higher patients' fear and scepticism and greater difficulties given by Covid-19 protocols (swaps, appropriate dressings, Covidpositive dedicated operating theatres) all made ordinary procedures slower and more intricate.

Overall CRC patients have suffered disadvantages from the Covid pandemic in terms of late diagnosis and more severe presentation, along with more advanced tumours, but the application of protocols and a good surgical performance have avoided greater hardships.

A not controllable factor, by national or regional health care system, has been and is up to today the fear of the general population to access health structures for follow-up visits and screening tests [26].

A large, published UK national population-based modelling study, showed that fear related to contracting COVID-19 has caused patients to be more apprehensive to seek medical care for routine or emergent issues [27].

This is proved by lower screening tests performed even when the service had reopened and by a higher number of patients referring to the emergency department with more severe symptoms as the first diagnostic approach [26, 27].

This should be kept into consideration for the future to have backup plans to guarantee prevention tests, visits and procedures to take place and not be suspended if new emergencies were to come.

\section{Conclusion}

Maintaining standards of care and validated protocols in emergency situations has proven to be the best decision: immediate reconstruction after BC surgery, laparoscopic and robotic access preferred to open and GI anastomosis performance were kept as first-line choices when possible.
As clearly comes out from our data and underlined once again in Sant'Anna's study [17], our region has managed to confirm a well-organised screening program, effective diagnosis and good surgical practice in critical conditions. We demonstrated to have solid and well-designed BC and CRC diagnostic and treatment protocols which can be applied and prove effective, whatever the emergency conditions.

The system held.

Despite these results, of a virtuous Italian region, the consequences of the diagnostic delay and the closure of the operating theatres could be catastrophic in terms of mortality and morbidity.

More research is needed to assess if the decreased screening rate during the SARS-CoV-2 pandemic resulted in delayed or missed diagnosis, different clinical management, or poorer outcomes.

Acknowledgements The authors thank all the General Surgery Unit Residents, Nurses, Surgeons and the entire staff for their cooperation.

Author contributions All authors have contributed significantly to the paper and read and approved the manuscript.

Funding No funds were obtained for this paper. There are no relationships with industry.

Availability of data and material Not applicable.

Code availability Not applicable.

\section{Declarations}

Conflict of interest There is no conflict of interest for all authors regarding the publication of this manuscript and no financial issues to disclose.

Ethics approval The manuscript reports an observational retrospective study, so, on the basis of the resolution of the Authority for the Protection of Personal Data (Gazzetta Uf-ciale $\mathrm{N}^{\circ} 72$; http://www.garan teprivacy.it/garante/doc.jsp?ID=1878276). This study was conducted in accordance with the ethical standards of the Declaration of Helsinki. The institutional ethical board approved the study and the informed consent was obtained under the institutional review board policies of hospital administration.

Statement of informed consent Informed consent was obtained from all individual participants included in the study.

Consent to participate Not applicable.

Consent for publication Not applicable.

\section{References}

1. Li X, Wang W, Zhao X et al (2020) Transmission dynamics and evolutionary history of 2019-nCoV. J Med Virol 92(5):501-511 
2. Zhu N, Zhang D, Wang W et al (2020) A novel coronavirus from patients with pneumonia in China, 2019. N Engl J Med 382(8):727-733

3. Bellato V, Konishi T, Pellino G et al (2020) Screening policies, preventive measures and in-hospital infection of COVID-19 in global surgical practices. J Glob Health 10(2):020507

4. Losurdo P, Giacca M, Biloslavo A et al (2020) Colorectal cancerscreening program improves both short- and long-term outcomes: a single-center experience in Trieste. Updates Surg 72(1):89-96

5. Force USPST, Davidson KW, Barry MJ et al (2021) Screening for colorectal cancer: US preventive services task force recommendation statement. JAMA 325(19):1965-1977

6. Arnold M, Sierra MS, Laversanne M, Soerjomataram I, Jemal A, Bray F (2017) Global patterns and trends in colorectal cancer incidence and mortality. Gut 66(4):683-691

7. Harbeck N (2020) Breast cancer is a systemic disease optimally treated by a multidisciplinary team. Nat Rev Dis Primers 6(1):30

8. Giudici F, Bortul M, Clagnan E et al (2020) Early effects of attendance to the Friuli Venezia Giulia (Northern Italy) mammography screening programme on the incidence of advanced-stage breast cancer: a cohort study. Epidemiol Prev 44(2-3):145-153

9. Giorgi D, Giordano L, Ventura L, Frigerio A, Paci E, Zappa M (2012) Mammography breast cancer screening in Italy: 2010 survey. Epidemiol Prev 36(6 Suppl 1):8-27

10. Stewart DB (2021) Updated USPSTF guidelines for colorectal cancer screening: the earlier the better. JAMA Surg 156:708

11. Berger BM, Parton MA, Levin B (2016) USPSTF colorectal cancer screening guidelines: an extended look at multi-year interval testing. Am J Manag Care 22(2):e77-81

12. Foca F, Mancini S, Bucchi L et al (2013) Decreasing incidence of late-stage breast cancer after the introduction of organized mammography screening in Italy. Cancer 119(11):2022-2028

13. Giuliano AE, Ballman KV, McCall L et al (2017) Effect of axillary dissection vs no axillary dissection on 10-year overall survival among women with invasive breast cancer and sentinel node metastasis: the ACOSOG Z0011 (Alliance) randomized clinical trial. JAMA 318(10):918-926

14. Giuliano AE, Edge SB, Hortobagyi GN (2018) Eighth edition of the AJCC cancer staging manual: breast cancer. Ann Surg Oncol 25(7):1783-1785

15. Sinha A, Gill SS (2018) Correlative study of cytological features in grading of invasive breast carcinoma. J Cytol 35(3):149-152

16. Hari DM, Leung AM, Lee JH et al (2013) AJCC Cancer Staging Manual 7th edition criteria for colon cancer: do the complex modifications improve prognostic assessment? J Am Coll Surg 217(2):181-190

17. Kaufman HW, Chen Z, Niles J, Fesko Y (2020) Changes in the number of US patients with newly identified cancer before and during the coronavirus disease 2019 (COVID-19) pandemic. JAMA Netw Open 3(8):e2017267

18. Van Haren RM, Delman AM, Turner KM et al (2021) Impact of the COVID-19 pandemic on lung cancer screening program and subsequent lung cancer. J Am Coll Surg 232(4):600-605

19. Tsai HY, Chang YL, Shen CT, Chung WS, Tsai HJ, Chen FM (2020) Effects of the COVID-19 pandemic on breast cancer screening in Taiwan. Breast 54:52-55

20. D'Ovidio V, Lucidi C, Bruno G, Lisi D, Miglioresi L, Bazuro ME (2021) Impact of COVID-19 pandemic on colorectal cancer screening program. Clin Colorectal Cancer 20(1):e5-e11

21. Rutter MD, Brookes M, Lee TJ, Rogers P, Sharp L (2021) Impact of the COVID-19 pandemic on UK endoscopic activity and cancer detection: a National Endoscopy Database Analysis. Gut 70(3):537-543

22. Dinmohamed AG, Visser O, Verhoeven RHA et al (2020) Fewer cancer diagnoses during the COVID-19 epidemic in the Netherlands. Lancet Oncol 21(6):750-751

23. Biganzoli L, Cardoso F, Beishon $\mathrm{M}$ et al (2020) The requirements of a specialist breast centre. Breast 51:65-84

24. Wilson AR, Marotti L, Bianchi S et al (2013) The requirements of a specialist breast centre. Eur J Cancer 49(17):3579-3587

25. Biganzoli L, Marotti L, Hart CD et al (2017) Quality indicators in breast cancer care: an update from the EUSOMA working group. Eur J Cancer 86:59-81

26. Jones D, Neal RD, Duffy SRG, Scott SE, Whitaker KL, Brain K (2020) Impact of the COVID-19 pandemic on the symptomatic diagnosis of cancer: the view from primary care. Lancet Oncol 21(6):748-750

27. Maringe C, Spicer J, Morris M et al (2020) The impact of the COVID-19 pandemic on cancer deaths due to delays in diagnosis in England, UK: a national, population-based, modelling study. Lancet Oncol 21(8):1023-1034

Publisher's Note Springer Nature remains neutral with regard to jurisdictional claims in published maps and institutional affiliations. 